\title{
VERSÓES DE SENTIDO: UM INSTRUMENTO FENOMENOLÓGICO-EXISTENCIAL PARA A SUPERVISÃO DE PSICOTERAPEUTAS INICIANTES
}

\author{
Georges Daniel Janja Bloc Boris*
}

\section{RESUMO}

O texto discute, num primeiro momento, os dilemas e conflitos do psicoterapeuta iniciante, propondo estratégias de solução para a sua superação. A formação do psicoterapeuta é contínua e sistemática, persistindo ao longo de sua vida profissional. Assim, não é um treinamento pontual e circunstancial, realizado num único momento, mesmo que determinante, como os últimos semestres do curso de psicologia. Em seguida, o texto discute os diversos instrumentos comumente utilizados na formação do psicoterapeuta, especialmente a fundamentação teórica, a própria psicoterapia do psicoterapeuta, bem como a supervisão por parte de um profissional experiente. Neste sentido, destaca a importância da supervisão e, finalmente, aponta os benefícios da adoção das "versões de sentido" (Amatuzzi, 1989, 1995, 2001) como instrumento de consolidação dos primeiros passos do psicoterapeuta iniciante. Por meio de tal método, o psicoterapeuta iniciante registra suas impressões sobre si mesmo, sobre o cliente e/ou sobre a sua relação com ele, expressando a experiência imediata como pessoa a respeito daquela situação. Desta forma, as versóes de sentido constituem um instrumento tanto objetivo quanto subjetivo, que facilita o trabalho de supervisão, pois pode revelar diversos sentidos da expressão do psicoterapeuta iniciante.

Palavras-chave: formação de psicoterapeutas; abordagens fenomenológico-existenciais; psicoterapia; supervisão; versões de sentido

* Mestre em Educação e Doutor em Sociologia pela Universidade Federal do Ceará; Professor Titular da Universidade de Fortaleza (UNIFOR). 
AbSTRACT

SENSE'S VERSIONS: A PHENOMENOLOGICAL-EXISTENTIAL TOOL FOR THE SUPERVISION OF PSYCHOTHERAPISTS IN TRAINING

The paper discusses, as a first step, dilemmas and conflicts of psychotherapists in training, proposing solution strategies for their overcoming. Psychotherapist's training is continuous and systematic, persisting along his/her professional lifetime. So, it is not a punctual and circumstantial training, made in an unique moment, even so in a significant one, as the last year of Psychology undergraduate degree. As a second step, the text discusses some tools usually used for the psychotherapist's training, specially the theoretical foundation, his/her own psychotherapy, as well the supervision of an experienced professional. In this way, the paper detaches the importance of supervision and, finally, it points out the benefits of adopting "sense's versions" (Amatuzzi, 1989; 1995; 2001) as an instrument for consolidating the first steps of psychotherapists in training. Using this method, helshe registers his/her impressions about him/herself, the client and/or their relationship, expressing his/her immediate experience as a person in that situation. Thereby, sense's versions constitute an objective and subjective tool that facilitates the supervision work because it may disclose several senses expressed by psychotherapists in training.

Keywords: psychotherapist's training; phenomenological-existential approaches; psychotherapy; supervision; sense's versions.

\section{INTRODUÇÃO}

Buys (1987) destaca que, embora a supervisão seja o mais importante segmento da formação do psicoterapeuta, há "muito pouco, ou quase nada, publicado sobre o assunto" (Buys, 1987: 11). É com o objetivo de favorecer o preenchimento de tal lacuna que me propus a elaborar este artigo. Neste sentido, apesar de me dirigir especialmente àqueles que se interessam pelo enfoque fenomenológicoexistencial, particularmente pela gestalt-terapia, penso que as consideraçôes que faço aqui servem a todos os que se iniciam na complexa arte de ser psicoterapeuta em diversos referenciais. Portanto, inicialmente, descrevo e discuto a situação vivida pelo psicoterapeuta iniciante, com seus dilemas e conflitos. Em seguida, analiso os diversos instrumentos comumente utilizados na formação do psicoterapeuta, como a fundamentação teórica e a importância da submissão a seu próprio processo psicoterápico, para, então, destacar a supervisão como uma ferramenta de aprendizagem essencial à sua formação. Finalmente, a partir de minha experiência como psicoterapeuta e supervisor, proponho e discuto o uso das versões de sentido (VS), conforme propostas por Amatuzzi (1989, 1995, 2001), como um instrumento facilitador da supervisão de psicoterapeutas iniciantes. 
Em minha experiência acadêmica, é com estranheza que percebo, com razoável freqüência, que muitos alunos chegam ao final do curso sem conhecimentos básicos ou experiência mínima quanto ao universo clínico, muitas vezes nem mesmo tendo se submetido a seu próprio processo psicoterápico, como se o estágio fosse apenas mais uma disciplina, que, cumprida, lhes proporcionaria o suficiente para se tornarem psicoterapeutas. Neste sentido, embora se pautando em outro referencial que não o enfoque fenomenológico-existencial, mas na psicanálise, Calligaris (2004) nos lembra que, até para o profissional experiente, "é sempre bom que um terapeuta, de vez em quando, volte a ser paciente" (Calligaris, 2004: 52). Acrescenta que a psicoterapia não pode ser uma demonstração pedagógica abstrata, não pode ser limitada a um fazer de conta durante o qual se transmitiria uma técnica. Ao contrário, espera-se que, nesta experiência, o futuro terapeuta se depare com a complexidade de suas motivaçóes, sintomas e fantasias conscientes e inconscientes. Pois, para o terapeuta, não há melhor introdução à variedade do sofrimento humano do que a descoberta de que, em algum canto de seus pensamentos, ele pode encontrar palavras, lembranças, razões, visóes e pensamentos parecidos com aqueles que afetam, agitam ou mesmo enlouquecem seus pacientes. No mesmo sentido, Ribeiro (1986) afirma que,

embora a psicoterapia vise diretamente à pessoa do cliente, é imprescindível uma reflexão adequada sobre a pessoa do psicoterapeuta, pois ele é mais importante como pessoa que o método ou sistema que utiliza. É mais significativo o que faz, transmite e vive que as técnicas ou a visão filosófica em que se fundamenta. O resultado e a eficiência da psicoterapia dependerão muito da grandeza e amplidão de sua personalidade (Ribeiro, 1986: 15-16).

Também observo que, terminado o estágio, apenas alguns psicoterapeutas iniciantes buscam formações específicas nas linhas teóricas que escolheram, e, infelizmente, quando elas terminam, a maioria deixa de acreditar que a supervisão de um psicoterapeuta mais experiente seja um recurso valioso e imprescindível na trajetória de qualquer psicoterapeuta. Tais observações constituem algumas das preocupações que me levaram a elaborar este texto, pois, lamentavelmente, ainda parecem permanecer como um dado comprometedor da formação dos psicoterapeutas iniciantes. Destaco que a formação de um psicoterapeuta é contínua e sistemática, persistindo ao longo de sua vida profissional e devendo ser sempre condizente com sua vida pessoal e as diversas opçôes e experiências que ele faz e vivencia. Não é, portanto, pontual e circunstancial, uma situação que se resolve apenas num único momento difícil, mesmo que determinante, como o dos últimos semestres de curso de psicologia. 


\section{O PSICOTERAPEUTA INICIANTE: DILEMAS E CONFLITOS}

Tavora (2001) destaca que:

ao iniciar o treinamento como terapeuta, os estudantes estão em diferentes estágios de amadurecimento pessoal e profissional. No entanto, todos se deparam com as mesmas angústias provocadas pelos primeiros contatos com os pacientes. No processo de internalização de um método de atendimento e definição de estilo pessoal, eles necessitam de uma orientação básica que possa guiar seus primeiros passos (Tavora, 2001: 23).

Por sua vez, Benjamin (1978) afirma que os psicoterapeutas iniciantes, freqüentemente, "estão tão preocupados com o que irão dizer em seguida que têm dificuldade em ouvir e absorver o que está acontecendo" (Benjamin, 1978: 25). É comum que os psicoterapeutas iniciantes tenham uma parca apreensão dos conceitos e dos temas dos enfoques teóricos que adotam, bem como de seus recursos técnicos e de seu manejo. Uma das possíveis razões deste limite é que, no caso das psicoterapias humanistas, elas surgiram, em grande parte, como uma reação ao positivismo, adotando, em muitas situações, posturas irracionalistas, antiintelectuais ou intuitivistas. Ginger \& Ginger (1995) reconhecem tal postura, particularmente no que se refere à gestalt-terapia: "seu principal mentor, Fritz Perls, tinha repugnância por qualquer teorização. 'Loose your head, come to your senses', gostava ele de repetir” (Ginger \& Ginger, 1995: 10-11). Entretanto, se o psicoterapeuta deve estar plenamente presente no processo psicoterápico, aí deve estar incluída, certamente, a sua racionalidade, sem excluir as vivências emocionais e intuitivas propiciadas por um enfoque de psicoterapia que se propõe a lidar com indivíduos plenos e sem dicotomias e com seu sofrimento psíquico. Como reação à sua carência teórica e técnica, o psicoterapeuta iniciante adota, muitas vezes, posturas escamoteadoras de sua insegurança, como tratarei mais profundamente adiante.

A omissão da realização de seu próprio processo psicoterápico pessoal é um sério agravante da situação do psicoterapeuta iniciante, com repercussões preocupantes no acompanhamento dos pacientes, como o mau manejo de sentimentos negativos, tanto do psicoterapeuta quanto do paciente. Entre outros motivos, a psicoterapia pessoal do próprio psicoterapeuta tem como justificativa o fato de que "quanto mais nos conhecemos, melhor podemos entender, avaliar e controlar nosso comportamento e melhor compreender e apreciar o comportamento dos outros. Quanto mais familiarizados conosco mesmos, menor a ameaça que sentimos diante do que encontramos" (Benjamin, 1978: 23). 
Pouca disponibilidade e descompromisso com a pessoa do paciente são bastante corriqueiros, voltando-se mais o psicoterapeuta iniciante a seus interesses ou a seu vínculo com a tarefa ou com a instituição. Tratando do compromisso do psicoterapeuta, Calligaris (2004) argumenta: "seu primeiro compromisso é com as pessoas que confiam em você e trazem para seu consultório uma queixa que pede para ser escutada e, por que não, resolvida. Ou, mais geralmente, seu primeiro compromisso é com a comunidade na qual você presta serviço. E o compromisso é de prestar o melhor serviço possível" (Calligaris, 2004: 98).

Desta forma, é razoavelmente comum que psicoterapeutas iniciantes estejam tão preocupados consigo mesmos que, lamentavelmente, podem mesmo esquecer seu compromisso com seus pacientes e/ou com suas tarefas.

A precariedade de seu auto-suporte interno pode levar o psicoterapeuta iniciante a buscar apoio excessivo no uso de técnicas ou mesmo na adesão rígida à teoria que fundamenta seu referencial psicoterápico em detrimento do desenvolvimento de uma atitude compreensiva, escamoteando sua própria insegurança. Assim, o psicoterapeuta iniciante percebe-se diante de uma lacuna angustiante: ao mesmo tempo que se percebe limitado a respeito do manejo adequado do referencial teórico-técnico que fundamenta a sua prática, é inexperiente em vivências pessoais e profissionais que possam lhe proporcionar maior confiança em si mesmo. É comum que se enfatize a importância essencial do embasamento teórico do psicoterapeuta, mas é menos freqüente que se discutam os riscos de um apego à teoria, ou seja, a tendência de muitos psicoterapeutas iniciantes a servir à teoria como uma defesa contra suas próprias dúvidas, adotando uma atitude formal, intelectual ou perfeccionista. "O terapeuta, desta forma, evita pensar no vínculo com o paciente, e acredita seriamente que os seus aspectos emocionais de-vem ser neutralizados e que só o seu intelectual deve existir para a compreensão do outro" (Cardoso, 1985: 14). Neste sentido, Calligaris (2004) alerta que "a orientação terapêutica na qual você se formou ou está se formando [...] não é uma ideologia, nem uma fé na qual seria preciso que você acreditasse, nem uma espécie de dívida que você contraiu com seus mestres e que o forçaria a se fazer seu repetidor e arauto fiel" (Calligaris, 2004: 65).

Além da importância do investimento na fundamentação teórico-técnica, Moreira (2001) destaca o valor da experiência vivida do psicoterapeuta iniciante para a sua formação, e, conseqüientemente, da submissão a seu próprio processo psicoterápico:

se o aprendiz não teve anteriormente a demanda de fazer uma psicoterapia, seguramente esta surgirá quando o terapeuta aprendiz comece o atendimento 
clínico. Trata-se de um momento que exige mais do que o conhecimento teórico no âmbito cognitivo; que vai mais além, incluindo o âmbito emocional e a necessidade de que o psicoterapeuta experimente um processo psicoterapêutico, com o fim de aprender sobre sua maneira de funcionar no mundo, sobre seus limites e potencialidades pessoais. Este autoconhecimento do psicoterapeuta será tão importante para seu desempenho profissional como o conhecimento da teoria e técnica da psicoterapia. Finalmente, [...] fundamental na formação do psicoterapeuta, será a supervisão, que se desenvolve na interseção dos dois momentos anteriores: o teórico e o experiencial. Trata-se do espaço de articulação entre o que o psicoterapeuta aprende e conhece sobre a teoria e seu paciente, e do que ele experimenta na relação terapeuta-paciente durante a sessão (Moreira, 2001: 311-312).

Tais problemas nos remetem à personalidade, à maturidade pessoal e profissional e ao autoconhecimento como variáveis essenciais à boa condução do processo psicoterápico. Calligaris (2004) destaca alguns traços de caráter que considera desejáveis em quem deseja se tornar psicoterapeuta: gosto pronunciado pela palavra; carinho espontâneo e extrema curiosidade pela variedade da experiência humana, gerada da variedade "animada" de sua própria vida, com o mínimo possível de preconceito; e uma boa dose de sofrimento psíquico. Neste sentido, nos lembra que:

é óbvio que uma psicoterapia não funciona nunca como a extirpação cirúrgica de um cisto ou como a exterminação de uma bactéria [...]. Uma psicoterapia é uma experiência que transforma; pode-se sair dela sem o sofrimento do qual a gente se queixava inicialmente, mas ao custo de uma mudança. $\mathrm{Na}$ saída, não somos os mesmos sem dor; somos outros, diferentes (Calligaris, 2004: 73).

É na mesma direção que Ribeiro (1986) destaca que "o psicoterapeuta não é um deus onipotente, é um homem consciente de suas fragilidades” (Ribeiro, 1986: 20).

É freqüente a idealização da figura do psicoterapeuta pelo paciente, que, associada à auto-idealização do próprio psicoterapeuta inexperiente, pode levá-lo a tentar corresponder a uma imagem onipotente e inacessível, ou a aceitar uma postura impotente e insignificante diante de seus pacientes. Para Calligaris (2004), "de fato, se a psicoterapia faz seu efeito, o paciente pára de idealizar o terapeuta" (Calligaris, 2004: 7). De fato, no processo psicoterápico, "há muitos momentos em que é inevitável que o paciente nos considere e nos use como modelos" (Ibid.: 148). Entretanto, “a identificação dos pacientes conosco nos impõe uma responsabilidade" (Ibid.: 149). Neste sentido, Cardoso (1985) destaca que a maioria dos 
psicoterapeutas, dos mais diferentes referenciais, concorda que a função da supervisão do psicoterapeuta iniciante é "levá-lo a perceber o quanto de idealizado existe em sua atuação, quanto de sua vivência como pessoa atua no processo terapêutico, sem esquecimento do natural auxílio ao seu desenvolvimento teórico e aperfeiçoamento técnico" (Cardoso, 1985: 11).

A auto-idealização pode conduzir o psicoterapeuta iniciante a um encantamento com seu próprio poder, ou a tentativas de sedução ou de punição do paciente, por exemplo. A postura onipotente pode se apresentar através de arrogância (que busca aparentar eficiência) ou de uma excessiva disponibilidade (que visa a atender a qualquer expectativa, necessidade ou exigência do paciente com o objetivo de ser reconhecido e admirado), escamoteando aparentemente a insegurança e a inexperiência do psicoterapeuta iniciante. Em alguns casos, ao adotar uma postura onipotente, o psicoterapeuta iniciante pode assumir uma atitude invasiva, desconsiderando a capacidade de o próprio paciente encontrar seus caminhos e suas alternativas de conduta. É neste sentido que Benjamin (1978) parece advertir que o psicoterapeuta deve "ter cuidado para não ajudar demasiado" (Benjamin, 1978: 17). Da mesma forma, Ribeiro (1999) destaca que "o psicoterapeuta não pode e não tem de decidir nada para o cliente, mas pode decidir com o cliente, num encontro profundo que de fato contamine a totalidade da relação" (Ribeiro, 1999: 29). Por sua vez, Calligaris (2004) considera que o processo psicoterápico é, geralmente, longo exatamente porque se espera que o psicoterapeuta direcione seu paciente, mas apenas favorecendo que ele se aproxime de seu próprio desejo. Entretanto, como a psicoterapia não é um espaço de realização dos desejos do psicoterapeuta - mas de conscientização do desejo do próprio paciente -, tal processo, muitas vezes, se revela empobrecido, frio ou mesmo contraproducente.

$\mathrm{Na}$ polaridade oposta ao psicoterapeuta onipotente, encontramos, com mais freqüência, o aprendiz que assume uma atitude impotente, mostrando-se inoperante por se sentir incapaz de lidar com emoções, experiências ou conteúdos - particularmente os negativos - do paciente, que lhe parecem acima das suas possibilidades de continência. O psicoterapeuta iniciante mostra-se, nestes casos, compreensivo, atencioso e disponível, mas não consegue intervir, propor ou aprofundar as questões reveladas pelo paciente, pois tal risco sugere uma situação excessivamente perigosa. Assim, ambas as posturas - onipotente e impotente - escamoteiam os limites e a real "potência" do psicoterapeuta iniciante, trazendo à tona seu dilema entre a técnica e a pessoa do técnico. Conforme Rojas-Bermúdez (1977), "pretender que um instrumento resolva tudo é persistir numa valorização ingênua, que servirá mais para proteger a própria onipotência do que o instrumento" (RojasBermúdez, 1977: 90). O uso da técnica deve ser cauteloso e fundamentado numa 
estratégia clínica que sintetize a teoria e a prática do psicoterapeuta e o vínculo entre vivência, compreensão, pensamento e ação entre psicoterapeuta e paciente. A técnica jamais deve ser proposta como um truque para resolver problemas, mas como um recurso facilitador da conscientização do paciente, utilizado quando ele já se dirige a algum tipo de ação determinada a partir de sua necessidade e de sua disponibilidade. Neste sentido, Moreira (2001) argumenta: "um dado de realidade que é fundamental: a solidão do terapeuta. No momento da sessão estará só, apesar de estar acompanhado por toda sua bagagem teórica e suas vivências pessoais, ademais das sugestôes e orientações do supervisor. Ali contará somente consigo mesmo, com ninguém mais; ele será o instrumento da psicoterapia" (Moreira, 2001: 314).

Para Calligaris (2004), nos processos psicoterápicos que acompanha, "o psicoterapeuta é, por assim dizer, ele mesmo o remédio" (Calligaris, 2004: 5). Muitas vezes, o psicoterapeuta iniciante busca suporte externo para seus dilemas, esquecendo-se de que sua própria pessoa é seu principal instrumento de trabalho, para além das técnicas e mesmo das teorias. Finalmente, Ribeiro (1986) assim resume o papel das técnicas no processo psicoterápico:

as técnicas são importantes, mas não podem ser exclusivas. As técnicas são instrumentos "mágicos", são "truques de ação". São importantes quando aplicadas em conseqüência do que já está ali e não aplicadas para produzir coisas, situações emocionais, etc. A técnica é aplicada para ajudar o psicoterapeuta a fazer uma leitura correta da situação e não para produzir fantasmas (Ribeiro, 1986: 76).

Cardoso (1985) aponta o fato de que muitos psicoterapeutas iniciantes vivenciam sintomas semelhantes aos de seus pacientes, o que gera dificuldade de contato ou envolvimento extremo, numa tentativa de resolver seus próprios problemas através do outro, ou inadequação das intervenções, levando freqüentemente o paciente à desistência do processo psicoterápico, ou, por vezes, ao abandono (concreto ou por meio de atitude de distanciamento) como um artifício por parte do psicoterapeuta iniciante. Especialmente nestas situações, é essencial que o psicoterapeuta busque suporte no seu próprio processo psicoterápico, na supervisão de profissionais experientes e competentes, bem como no necessário envolvimento com o estudo teórico do enfoque adotado. Para Guedes (1985), “ser terapeuta é um privilégio. [...] [Sua]... arte é 'tocar' as pessoas. 'Tocar' pela palavra, gesto, afeto, expressão, olhar, mo-vimentos, etc, nos seus pontos sensíveis, adormecidos, cristalizados, encantados. Eu consigo 'tocar' quando fui ou estou sendo to-cado por essa mesma pessoa” (Guedes, 1985: 15). 
A possibilidade de tocar e de ser tocado - no sentido de sensibilizar e de se envolver com o mundo existencial do paciente - gera, muitas vezes, no psicoterapeuta iniciante, temor da relação psicoterapêutica ou encantamento com seu próprio poder, encobrindo a sua polaridade oposta, ou seja, o fato de que, freqüentemente, pode ser tocado por seus pacientes. Acredito que grande parte das dificuldades dos psicoterapeutas iniciantes diga respeito a um desconhecimento e a uma confusão quanto a como lidar com os sentimentos gerados pelos e nos pacientes, bem como à parca conscientização das tarefas da psicoterapia e do psicoterapeuta.

A tarefa da psicoterapia, conforme Cardoso (1985), inclui o conhecimento teórico, a vivência técnica, o vínculo autêntico com o paciente, a satisfação com o trabalho, além do desenvolvimento pessoal do outro e de si mesmo como seres humanos. Portanto, requer do psicoterapeuta uma síntese pessoal da teoria e da técnica, de forma a não escravizá-lo nem a uma nem à outra. Um exemplo de nãoescravização à teoria e à técnica diz respeito às regras do processo psicoterápico, um freqüente motivo de "empacamento" do psicoterapeuta iniciante. Apesar de serem essenciais para um claro vínculo entre psicoterapeuta e paciente, as normas devem ser, de fato, digeridas e assimiladas pelo psicoterapeuta, que precisa dar-lhes sentido, torná-las flexíveis e contextualizá-las.

Podemos definir a psicoterapia como um processo interpessoal que envolve psicoterapeuta e paciente por meio de contatos verbais e não-verbais, com objetivo definido de auxílio às dificuldades emocionais do paciente, visando à sua própria integração à vida (Cardoso, 1985). A definição dos objetivos específicos do processo psicoterápico é uma variável importante, na medida em que o cont(r)ato terapêutico, se mal definido, mal estruturado ou mal esclarecido, pode levar a fracassos consideráveis. A integração e a vinculação do processo psicoterápico com a vida pessoal do paciente, por sua vez, é uma meta básica, pois, de outra forma, corre-se o risco de criar uma vivência dicotômica, na qual a teoria não se coaduna com a prática, as sessões são incongruentes com as experiências "fora" da psicoterapia e o espaço psicoterápico equivale a um "paraíso" ilusório e idealizado ou a um "depósito" seguro, mas inócuo, e a vida do paciente a um "inferno" ameaçador e insuportável.

A literatura teórica é um ponto de apoio essencial e de referência ao psicoterapeuta, mas não basta por si mesma, devendo sempre ser adotada com flexibilidade, fundamentando e sendo fundamentada pela prática profissional, pelas vivências pessoais, pela supervisão e pela psicoterapia do próprio psicoterapeuta. Neste sentido, as atitudes e as posturas do psicoterapeuta "não podem ser ensinadas, mas podem ser aprendidas. Estas atitudes básicas são: fé, confiança, aceitação 
e respeito" (Cardoso, 1985: 21). Fé e confiança se referem à crença no potencial do paciente de encontrar seu próprio caminho. Aceitação e respeito são atitudes compreensivas fundamentais na facilitação da busca do paciente por meio do encontro existencial propiciado pela psicoterapia. Assim, as atitudes do psicoterapeuta são essencialmente educativas, visando não apenas à apreensão de determinados conteúdos, mas constituindo uma "pedagogia da vida" (Boris, 1992: 62) no sentido de uma forma de (re)aprendizagem de novas alternativas para que o paciente possa viver de maneira mais saudável ou, pelo menos, com menos sofrimento psíquico.

Bleger (1975) considera que o psicoterapeuta vivencia grande ansiedade, pois se confronta com um objeto de estudo e de trabalho semelhante a si mesmo, lidando com as contingências e as vicissitudes comuns tanto ao psicoterapeuta quanto ao paciente: ambas são dados de humanidade que os aproximam, mas que podem confundir os parceiros da relação psicoterápica. Neste sentido, mesmo não sendo um psicanalista, Ribeiro (1986) adverte que,

com o mesmo nome ou com nomes diferentes, a contratransferência está presente em todas as técnicas e pode interferir no processo psicoterapêutico. Sua análise é, sem dúvida alguma, o único caminho lógico e produtivo que o psicoterapeuta encontra para compreender momentos difíceis por ele experienciados no processo psicoterapêutico e para impedir que sua relação resvale por caminhos que certamente não conduzem o cliente a um encontro real consigo próprio (Ribeiro, 1986: 125).

Acrescenta, no que se refere ao psicoterapeuta, que,

através da análise de sua contratransferência, ele pode conhecer melhor o seu comportamento, percebendo o que o cliente produz inconscientemente nele e como ele funciona, vendo seu cliente em ação. Ele deve estar totalmente aberto para deixar-se invadir pelo mundo interior de seu cliente. Esta atitude poderá produzir nele ansiedade, desencorajamento, medo ou amor, afeto ou interesse. $\mathrm{O}$ psicoterapeuta poderá igualmente sentir-se ameaçado, enquanto a atitude do cliente poderá co-envolvê-lo de modo emocional para uma resposta de contratransferência positiva ou negativa. [...] Quando o psicoterapeuta tem consciência de sua contratransferência ele sente mais facilidade para analisar a transferência do cliente, na mesma linha que esta produzia nele a contratransferência. Quando permanece inconsciente, a contratransferência pode acarretar a estagnação e, por fim, o fracasso do processo psicoterapêutico. A elaboração da transfe- 
rência depende das atitudes contratransferenciais do psicoterapeuta (Ribeiro, 1986: 94).

Não se trata, aqui, de privilegiar as concepções psicanalíticas de transferência e de contratransferência no arcabouço teórico-técnico das abordagens fenomenológico-existenciais - obviamente, um contra-senso -, mas de reconhecer que a diferença do psicoterapeuta em relação ao cliente está baseada na sua atitude compreensiva, um esforço racional e emocional para compreender a si mesmo e ao outro, reconhecendo seus próprios equívocos e sentimentos em relação a ele e àquilo que ambos representam. Desta forma, para Calligaris (2004), a função do psicoterapeuta não é ensinar seus pacientes nem "mexer" com suas vidas, mas favorecer a conscientização dos desejos deles. Portanto, "a grande habilidade do terapeuta, então, seria a de poder perceber os aspectos transferidos em sua pessoa e, por outro lado, poder conhecer a realidade dos seus sentimentos, para que não se mesclem aos do paciente, o que tem sido apontado como causa freqüente de insucesso da terapia" (Cardoso, 1985: 21).

Entretanto, é importante ter em mente que nem todos os sentimentos vivenciados na relação psicoterápica são apenas transferenciais. Da mesma forma, devemos reconhecer que a transferência e a contratransferência - ou outras denominaçôes que prefiramos - são fenômenos que ocorrem freqüentemente nas relações humanas, particularmente na psicoterapia. Adotando uma perspectiva gestáltica, podemos compreender os sentimentos transferenciais e contratransferenciais - bem como algumas outras emoções vividas no processo psicoterápico como experiências projetivas, pois, nestes casos, o paciente e/ou o psicoterapeuta tendem a "se desapropriar das partes de seus próprios impulsos, mas também para se desapropriar das partes de si em que surgem os impulsos" (Perls, 1977: 50). Talvez um caminho sensato nesta questão seja o proposto por Amatuzzi (1989):

"trata-se não de interpretar $a$ transferência mas de interpretar $n a$ transferência". A diferença entre o $a$ (transferência) e o na (transfe-rência) é exatamente a diferença entre entrar ou não na relação. E o termo "interpretação" pode ser entendido no sentido em que se identifica com a própria expressão do terapeuta (compreensiva da presença total e intencional do paciente) e, portanto, interpretação fundadora do terapeuta exatamente em sua vivência da relação" (Amatuzzi, 1989: 176).

Nesta direção, Amatuzzi adverte ainda que, no processo psicoterápico, "há lugar, apesar de tudo, para interpretações intelectuais, mas desde que o sentido do 
todo da relação não seja dado por semelhantes interpretações, mas pelo vai-e-vem de respostas autênticas baseadas num ouvir profundo" (Amatuzzi, 1989: 176; nota de rodapé).

As várias questões levantadas acima me levam a destacar que ser psicoterapeuta requer uma síntese pessoal de um conjunto de atitudes desenvolvidas a partir de atividades ligadas à própria vida do psicoterapeuta, entre as quais se incluem a supervisão de profissionais competentes e experientes, a inserção em seu processo psicoterápico particular, a abertura à diversidade das experiências humanas, o desenvolvimento de seu estilo pessoal e profissional, a admissão em processos de formação ou de treinamento sistemáticos e o estudo dedicado aos fundamentos e aos temas do enfoque adotado.

\section{VERSÕES DE SENTIDO: UM INSTRUMENTO FENOMENOLÓGICO-EXISTEN- CIAL PARA A SUPERVISÃO DE PSICOTERAPEUTAS INICIANTES}

Assim, passo, então, a discutir as versões de sentido, conforme propostas por Amatuzzi (1989, 1995, 2001), como um importante instrumento fenomenológicoexistencial a ser utilizado na supervisão de psicoterapeutas iniciantes. Aqui, é importante lembrar, como Calligaris (2004) destaca, que "a supervisão não é uma aula de clínica ou de arte diagnóstica. Também não é a ocasião para o supervisor mostrar como e por que ele teria agido diferente de você. A função da supervisão de um jovem terapeuta ou analista, salvo situações catastróficas, deve ser autorizar o terapeuta, inspirar-lhe confiança..." (Calligaris, 2004: 124).

Creio que a grande dificuldade dos processos de supervisão, particularmente na clínica-escola, deve-se à sua semelhança e, ao mesmo tempo, à sua diferença em relação à própria psicoterapia. Se, por um lado, a supervisão não se propõe a ser um espaço de intervenção do supervisor nas questóes pessoais e íntimas dos psicoterapeutas iniciantes, por outro lado, sem uma real compreensão do vínculo entre seus temas existenciais e os processos que ele acompanha, a supervisão corre o risco de tornar-se um mero estudo teórico-técnico distanciado. O grande desafio é, portanto, como articular estes dois pólos, sem confundi-los.

Há alguns anos, utilizo um instrumento que acredito que enfrente melhor tal desafio. São as versões de sentido, propostas por Amatuzzi (1995), que, sinteticamente, assim as descreve:

no fim de cada sessão de um atendimento terapêutico, imediatamente após seu término, escrevemos alguma coisa. Isso que escrevemos não pretende ser um 
relato do que aconteceu em sua materialidade, mas uma tentativa de dizer a experiência imediata do terapeuta enquanto pessoa naquele momento, e enquanto ainda referida à sessão que acaba de terminar (Amatuzzi, 1995: 68).

Em seguida, aponta as características das versōes de sentido, considerando-o um instrumento que:

1. [...] é tanto objetivo como subjetivo, uma vez que se trata da experiência do terapeuta enquanto intencional, isto é, referida ao atendimento que termina; 2. é ao mesmo tempo um sentido captado e um sentido produzido: somente o percebo quando o produzo como participante da relação;

3. ele é uno e múltiplo, isto é, pode se desdobrar em outros sentidos em atos sucessivos de expressão;

4. ele somente aparece quando o próprio ato de o expressar fizer sentido ele também (Amatuzzi, 1995: 68-69).

Conforme Bernard \& Goodyear (1992), o instrumento "tem também um aspecto fenomenológico, pois assume que as próprias pessoas são os melhores intérpretes de suas experiências" (Bernard \& Goodyear, 1992: 26). Para Moreira (2001), a descrição da experiência imediata do psicoterapeuta por meio das versões de sentido é capaz de revelar a maior quantidade possível de vivências compartilhadas entre psicoterapeuta e paciente. Entretanto, tal descrição não é meramente cognitiva nem necessariamente detalhada. $\mathrm{O}$ psicoterapeuta sob supervisão deve escrever, livre e espontaneamente, logo após a sessão, tudo o que lhe ocorra sobre a relação psicoterápica, sobre o paciente e sobre si mesmo:

imagens, metáforas, sentimentos seus ou do paciente, qualquer coisa. Busca-se alcançar o sentido da sessão, tal como a vive o terapeuta na relação com o paciente, destacando na versão de sentido o que toca o terapeuta, quer dizer, o que se produz nele a partir da relação com o paciente, como lhe chegam os conteúdos trabalhados na sessão, assim como impressões e sentimentos suscitados a partir deles. Através da versão de sentido, busca-se entrar em contato com as sensações originadas da relação terapeuta-paciente e clarificar a percepção do terapeuta para compreender o significado do material trabalhado durante a sessão no contexto do processo psicoterapêutico (Moreira, 2001: 315-316).

Assim, a versão de sentido:

diferencia-se de um informe da sessão (que prioriza a descrição objetiva do diálogo desenvolvido ou de uma transcrição de gravação da sessão) em que a 
descrição enfatiza as sensações do terapeuta a partir da descrição do vivido, buscando alcançar a essência e a dinâmica do processo; portanto, vai muito mais além do simples registro. Pode ser composta tanto por percepções do paciente, como de sentimentos de angústia ou de êxito do terapeuta supervisionado: as dúvidas, medos e alegrias na solidão da situação de atendimento. Registrar o processo psicoterapêutico através da versão de sentido significa transformar o estado bruto das sessões em algo com sentido; significa fazer emergir uma teorização sobre o vivido, e permitindo a visão mais aguda do processo do paciente através da experiência da relação terapeuta-paciente (Moreira, 2001: 316).

Deste modo, podemos deduzir que as versões de sentido constituem uma ferramenta enriquecedora da supervisão de psicoterapeutas iniciantes, especialmente na clínica fenomenológico-existencial, mas podendo mesmo ser aplicadas em outros referenciais, pois "consiste numa fala expressiva da experiência imediata de seu autor, face a um encontro recém-terminado" (Amatuzzi, 2001: 74). Trata-se de "um registro condensado do vivido", pois permite "à pessoa não apenas lembrar-se do ocorrido, mas também falar disso de forma viva, atual, como pela primeira vez, explicitando detalhes do vivido" (Amatuzzi, 2001: 76). Finalmente, podemos considerar que "uma VS bem feita é uma espécie de radiografia fenomenológica de um encontro" (Amatuzzi, 2001: 77).

\section{CONSIDERAÇÕES FINAIS}

Portanto, creio que as versões de sentido respondem bem a alguns dilemas e conflitos do psicoterapeuta iniciante e aos problemas que se manifestam nas várias fases que costumo perceber nos processos de supervisão:

1. num primeiro momento, os psicoterapeutas iniciantes têm necessidade de descrever e de discutir todas as sessóes de seus diversos pacientes, o que torna a supervisão freqüentemente mecânica, numa alternância entre "o paciente disse isso" e "eu respondi aquilo", conferindo com o supervisor se agiram "corretamente". Nesta fase, as versôes de sentido podem constituir um importante recurso de acesso e de exploração do mundo existencial do psicoterapeuta e de sua relação com os pacientes;

2. mais adiante e aos poucos, os psicoterapeutas iniciantes passam a selecionar as situações e os momentos psicoterapêuticos mais significativos, levando à supervisão não mais todas as sessões de todos os pacientes, mas a situação geral daqueles pacientes que acompanham ou, mais especificamente, dos que os preocupam mais. Neste estágio, as versões de sentido acrescentam aos psicoterapeutas 
iniciantes mais versatilidade e flexibilidade diante de pacientes que os tocam mais significativamente ou que mais absorvem sua atenção;

3. finalmente, se o processo avança, o foco da supervisão deixa de ser unicamente o paciente e seus problemas, passando a se constituir num contexto mais amplo, no qual o psicoterapeuta iniciante está, de fato, diante de um referido paciente, que provoca tais ou quais repercussões nele. É nesta fase que as versões de sentido podem ser mais ricamente exploradas, pois elas podem incluir mais expressivamente as vivências da pessoa do psicoterapeuta iniciante, que pode analisar e discutir melhor, na supervisão, sua atuação nos processos psicoterápicos que acompanha.

Encerro este texto com as palavras do criador das versões de sentido, Amatuzzi (2001), destacando as qualidades de tal instrumento para a supervisão de psicoterapeutas:

ele pode ser um indicador indireto (mas o mais direto que podemos dispor) do sentido do encontro. Ele é uma versão do sentido do encontro, tal como ele existe no presente da experiência dessa pessoa. E é quando utilizada dessa forma que uma VS pode ser um instrumento útil em pesquisa e formação. [...] No caso de um terapeuta, ela ajuda a torná-lo mais disponível para o próximo encontro na medida em que foi ouvida por alguém (e compreendida), ou ao menos pronunciada conscientemente por seu autor. Em supervisão, pois, a VS "traz" seu autor, traz seu projeto, dá-o a conhecer nesse novo contexto de interlocução. E esta é justamente uma das finalidades da supervisão (Amatuzzi, 2001: 82-84).

\section{REFERÊNCIAS BIBLIOGRÁFICAS}

Amatuzzi, M. (1989). O resgate da fala autêntica: filosofia da psicoterapia e da educação. Campinas: Papirus. . (1995). Descrevendo processos pessoais. Estudos de Psicologia, 12, 1, 65-79. . (2001). Versão de sentido. In Por uma psicologia humana (pp. 73-86). Campinas: Alínea.

Benjamin, A. (1978). A entrevista de ajuda. São Paulo: Martins Fontes.

Bernard, J. M. \& Goodyear, R. K. (1992). Fundamentals of clinical supervision. Boston: Allyn and Bacon.

Bleger, B. (1975). Temas de psicologia. Buenos Aires: Nueva Visión. 
Boris, G. D. J. B. (1992). O processo de cooperação na psicoterapia de grupo em gestaltterapia. Dissertação de Mestrado. Programa de Pós-Graduação em Educação, Universidade Federal do Ceará, Fortaleza, CE.

Buys, R. C. (1987). Supervisão de psicoterapia na abordagem humanista centrada na pessoa. São Paulo: Summus.

Calligaris, C. (2004). Cartas a um jovem terapeuta: reflexóes para psicoterapeutas, aspirantes e curiosos. Rio de Janeiro: Elsevier.

Cardoso, E. R. G. (1985). A formação profissional do psicoterapeuta. São Paulo: Summus. Ginger, S. \& Ginger, A. (1995). Gestalt: uma terapia do contato. São Paulo: Summus.

Guedes, A. M. (1985). Abel Marcos Guedes. In Porchat, I. \& Barros, P. (orgs.). Ser terapeuta: depoimentos (pp. 15-26). São Paulo: Summus.

Moreira, V. (2001). Más allá de la persona: hacia una psicoterapia fenomenológica mundana. Santiago: Editorial de la Universidad de Santiago de Chile.

Perls, F. (1977). A abordagem gestáltica e testemunha ocular da terapia. Rio de Janeiro: Zahar.

Ribeiro, J. P. (1986). Teorias e técnicas psicoterápicas. Petrópolis: Vozes. . (1999). Gestalt-terapia de curta duração. São Paulo: Summus.

Rojas-Bermúdez, J. G. (1977). Introdução ao psicodrama. São Paulo: Mestre Jou.

Tavora, M. T. (2001). Treinamento em psicoterapia individual, de grupo e de casal: um guia para supervisores e terapeutas iniciantes. Fortaleza: Casa de José de Alencar/Programa Editorial.

Recebido em 17 de setembro de 2007 Aceito para publicação em 27 de abril de 2008 